\title{
Risk factors associated with impaired ovarian reserve in young women of reproductive age with Crohn's disease
}

\author{
Yue Zhao ${ }^{1 *}$, Baili Chen ${ }^{1 *}$, Yao He ${ }^{1}$, Shenghong Zhang ${ }^{1}$, Yun Qiu ${ }^{1}$, Rui Feng ${ }^{1}$, Hongsheng Yang $^{1}$, Zhirong Zeng ${ }^{1}$, \\ Shomron Ben-Horin ${ }^{1,2}$, Minhu Chen ${ }^{1}$, Ren Mao ${ }^{1}$ \\ ${ }^{1}$ Department of Gastroenterology, The First Affiliated Hospital, Sun Yat-Sen University, Guangzhou, China; ${ }^{2}$ Department of Gastroenterology, \\ Sheba Medical Center, Sackler School of Medicine, Tel-Aviv University, Tel-Aviv, Israel
}

Background/Aims: Crohn's disease (CD) primarily affects young female adults of reproductive age. Few studies have been conducted on this population's ovarian reserve status. The aim of study was to investigate potential risk factors associated with low ovarian reserve, as reflected by serum anti-Müllerian hormone (AMH) in women of reproductive age with CD. Methods: This was a case-control study. Cases included 87 patients with established CD, and healthy controls were matched by age, height and weight in a 1:1 ratio. Serum AMH levels were measured by enzyme-linked immunosorbent assay. Results: The average serum AMH level was significantly lower in CD patients than in control group $(2.47 \pm 2.08 \mathrm{ng} / \mathrm{mL}$ vs. $3.87 \pm 1.96 \mathrm{ng} / \mathrm{mL}$, respectively, $P<0.001)$. Serum AMH levels were comparable between CD patients and control group under 25 years of age $(4.41 \pm 1.52$ $\mathrm{ng} / \mathrm{mL}$ vs. $3.49 \pm 2.10 \mathrm{ng} / \mathrm{mL}, P=0.06)$, however, serum AMH levels were significantly lower in CD patients over 25 years of age compared to control group $(P<0.05)$. Multivariable analysis showed that an age greater than 25 (odds ratio $[\mathrm{OR}], 10.03 ; 95 \%$ confidence interval [CI], 1.90-52.93, $P=0.007)$, active disease state (OR, 27.99; 95\% CI, 6.13-127.95, $P<0.001)$ and thalidomide use (OR, 15.66; 95\% CI, 2.22-110.65, $P=0.006$ ) were independent risk factors associated with low ovarian reserve (serum AMH levels $<2 \mathrm{ng} / \mathrm{mL}$ ) in CD patients. Conclusions: Ovarian reserve is impaired in young women of reproductive age with CD. Age over 25 and an active disease state were both independently associated with low ovarian reserve. Thalidomide use could result in impaired ovarian reserve. (Intest Res 2020;18:200-209)

Key Words: Crohn disease; Ovarian reserve; Anti-Mullerian hormone

\section{INTRODUCTION}

Crohn's disease (CD) is a chronic and recurrent intestinal inflammatory disorder that typically affects young females of reproductive age ${ }^{1-7}$ Previous retrospective studies suggest that $\mathrm{CD}$ is associated with decreased fertility rate. ${ }^{8-14} \mathrm{CD}$-associated inflammation in the pelvis, including the fallopian tubes and ovaries, as well as surgery-related chronic tubal adhesions,

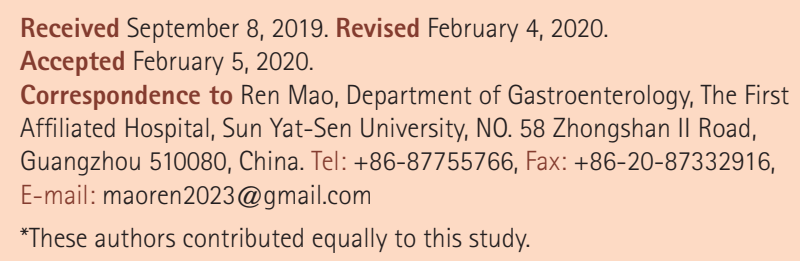

could potentially affect fertility of female CD patients. ${ }^{15-19}$ In addition, voluntary childlessness due to excessive anxiety and lack of disease knowledge could also lead to a decreased fertility rate. ${ }^{20}$

Ovarian reserve, which reflects the quantity and quality of oocytes in the ovary, is an indicator of fertility in females of reproductive age. ${ }^{21,22}$ Conventional hormonal tests, including follicle-stimulating hormone (FSH), luteinizing hormone and estrogen, have been utilized to evaluate ovarian reserve. However, these methods are limited, as sample collection is required on a specific day of the menstrual cycle. ${ }^{23}$ Anti-Müllerian hormone (AMH), a new hormone marker of ovarian reserve, can be measured on any day of the menstrual cycle, as it remains stable throughout the cycle. ${ }^{24,25}$ As an early, reliable and quan- 
titative indicator, AMH is considered the most accurate hormonal marker of ovarian reserve. ${ }^{26}$

To date, only limited data regarding serum AMH levels in female CD patients is available with inconsistent findings. ${ }^{27-29} \mathrm{In}$ the study reported by Şenateş et al., ${ }^{28} \mathrm{AMH}$ was measured in a relatively small sample of $35 \mathrm{CD}$ patients, and AMH levels in CD patients were significantly lower compared to the controls. However, in another study including 50 patients with $\mathrm{CD}^{27}$ no statistical difference was found between mean serum AMH levels in CD and control women. Moreover, risk factors associated with decreased ovarian reserve remain unclarified. ${ }^{27,29}$ This is an important knowledge gap that identifying risk factors associated with decreased ovarian reserve could help to prevent impairment of ovarian reserve. The aim of the current study was to both investigate AMH level alteration in female CD patients and identify independent risk factors affecting decreased AMH levels in a case-control study based on sample size calculation.

\section{METHODS}

\section{Study Design and Population}

We performed an individually matched, case-control crosssectional study at the First Affiliated Hospital of Sun Yat-Sen University, a tertiary IBD referral center, from January 2013 to March 2018. Reproductive age was defined as 18 to 45 years old. ${ }^{20} \mathrm{CD}$ diagnosis was defined through clinical manifestations and endoscopic, radiologic, and histopathological findings. ${ }^{3}$ Exclusive criteria were: age less than 18 years old or more than 45 years old, oral contraceptive taking history, a gynecological and endocrine relevant surgical history, cytotoxic drugs history, pelvic radiotherapy history, diagnosed or potential polycystic ovary syndrome, thyroid disease, hyperprolactinemia or other relevant diseases, diagnosed or potential malignancies or other gynecological organic diseases. ${ }^{27,28}$ Healthy controls were recruited from local communities. Controls were matched with CD patients for age, height and weight in a 1:1 ratio, non-pregnancy and not taking oral contraceptive. We obtained informed consent from all cases and controls. The study protocol was approved by the Clinical Research Ethics Committee of the First Affiliated Hospital of Sun Yat-Sen University (IRB No. 2015-47).

\section{AMH Measurement}

Ovarian reserve was determined by serum AMH levels measured by ELISA (AMH Gen II ELISA, Kangrun Biotech Co., Ltd.,
Guangzhou, China) in duplicate samples for the cases and controls as previously reported. ${ }^{24}$ Briefly, blood samples were collected from the cubital vein of all included subjects after a 12-hour fast. Blood samples were centrifuged at 2,000 $\mathrm{g}$ for 15 minutes at $4^{\circ} \mathrm{C}$ within 2 hours of venipuncture. All serum samples were immediately stored in polypropylene tubes at $-80^{\circ} \mathrm{C}$ until further analysis. The range of detection was 0.05 to 15.93 $\mathrm{ng} / \mathrm{mL}$ with intra- and inter-assay coefficients of variation below or equal to $4.71 \%$ and $5.87 \%$. To minimize the chance of bias in the assay, all sera were processed on the same day, using the same measurement kits, and by the same operator.

\section{Definitions}

Low ovarian reserve was defined as serum AMH levels below $2 \mathrm{ng} / \mathrm{mL} \cdot{ }^{27,30} \mathrm{In}$ an additional analysis, diminished ovarian reserve was also pragmatically defined as serum AMH levels below $1.1 \mathrm{ng} / \mathrm{mL} .{ }^{31} \mathrm{CD}$ activity was evaluated by the CDAI. Patients with a CDAI score less than 150 were considered to be in remission, and a CDAI score over 150 was considered active. The chronic diarrhea was defined as loose or watery stools $>25 \%$ of the time without predominant abdominal pain or bloating (criterion fulfilled for the last 3 months with symptom onset at least 6 months before diagnosis and patients meeting criteria for diarrhea-predominant IBS should be excluded). ${ }^{32}$

\section{Sample Size Calculation}

The sample size was determined based on a level of significance, two-sided test at $\alpha=0.05$ and power (1- $\beta$ ) of 0.8 with sampling ratio of $1: 1{ }^{33}$ This calculation was based on an estimated number of possible cases with low AMH levels in the $\mathrm{CD}$ and control groups. ${ }^{27}$ These data were combined with several assumptions to determine that a sample size of $60 \mathrm{sub}-$ jects in each group would have an $80 \%$ power to detect a difference in low AMH level events.

\section{Statistical Analysis}

All statistical data were analyzed with SPSS version 12.0 software (SPSS Inc., Chicago, IL, USA). An unpaired $t$-test and paired $t$-test were used for normally distributed data, and the Wilcoxon signed-rank test was used for non-normally distributed data. Dichotomized variables were compared using a chi-square test or Fisher two-tailed test. A logistic regression was constructed with the most informative variables. Only variables with $P<0.10$ were retained in the final model using a forward stepwise approach. Adjusted OR and 95\% CI were derived from 
the estimated regression coefficients. A two-tailed $P$-value $<0.05$ was considered to be significant.

\section{RESULTS}

\section{Patient Demographic Characteristics}

A total of 87 female CD patients and 87 healthy controls were included in the final analysis. The demographic and clinical characteristics are presented in Table 1. The median CD duration was 6.1 years (range, 0.3-15.6 years). Forty-three CD patients were in an active disease state and 44 were in remission. Seven CD patients had not used any medical treatment. The remaining patients had received at least 1 month of medical treatment prior to blood sample collection, including 11 patients who received 5-aminosalicylic acid (5-ASA), 5 patients who received steroids, 39 patients who received azathioprine (AZA), 21 patients who received thalidomide, and 4 patients who received infliximab.

\section{AMH levels in CD Patients and Healthy Controls}

The comparison and distribution of serum AMH levels in CD patients and matched healthy controls are presented in Fig. 1A. The mean serum AMH level in CD patients $(2.47 \pm 2.08 \mathrm{ng} / \mathrm{mL})$

Table 1. Baseline Demographic and Clinical Characteristics of the Patients and Healthy Controls

\begin{tabular}{lccc}
\hline Characteristic & $\begin{array}{c}\text { CD patient } \\
(\mathrm{n}=87)\end{array}$ & $\begin{array}{c}\text { Control } \\
(\mathrm{n}=87)\end{array}$ & $P$-value \\
\hline Age (yr) & $30(18-45)$ & $30(18-45)$ & 0.933 \\
Age distribution (yr) & $31(36)$ & $31(36)$ & 1.000 \\
$18-25$ & $20(23)$ & $20(23)$ & 1.000 \\
$26-30$ & $16(18)$ & $16(18)$ & 1.000 \\
$31-35$ & $10(11)$ & $10(11)$ & 1.000 \\
$36-40$ & $10(11)$ & $10(11)$ & 1.000 \\
$41-45$ & $159.5 \pm 3.5$ & $160.7 \pm 3.6$ & 0.423 \\
Height (cm) & $50.9 \pm 6.4$ & $54.8 \pm 6.8$ & 0.335 \\
Weight (kg) & $20.4 \pm 2.3$ & $21.4 \pm 2.8$ & 0.062 \\
BMI (kg/m $\left.{ }^{2}\right)$ & $46(53)$ & $56(64)$ & 0.915 \\
Participants with children & $5(6)$ & $4(5)$ & 0.732 \\
Participants with miscarriage & & & \\
Family history of Gl diseases & $3(3)$ & 0 & 0.081 \\
Inflammatory disease & $7(8)$ & $8(9)$ & 0.787 \\
Gl tumor & $3(3)$ & $2(2)$ & 0.650 \\
\hline Chronic diarrhea & & & \\
\hline
\end{tabular}

Values are presented as median (range), number (\%), or mean \pm SD. was significantly lower than that of the control group $(3.87 \pm 1.96$ $\mathrm{ng} / \mathrm{mL}, P<0.001)$. In the paired comparison, statistical difference was also found between CD patients and matched controls $(P<0.001)$ (Fig. 1B). When groups were divided based on age, serum AMH levels were comparable between CD patients and healthy controls for patients younger than 25 years old $(4.41 \pm 1.52 \mathrm{ng} / \mathrm{mL}$ vs. $3.49 \pm 2.10 \mathrm{ng} / \mathrm{mL}, P=0.06)$, however, serum AMH levels were significantly lower in CD patients older than 25 years $(P<0.05$ for all comparisons) (Fig. 1C).
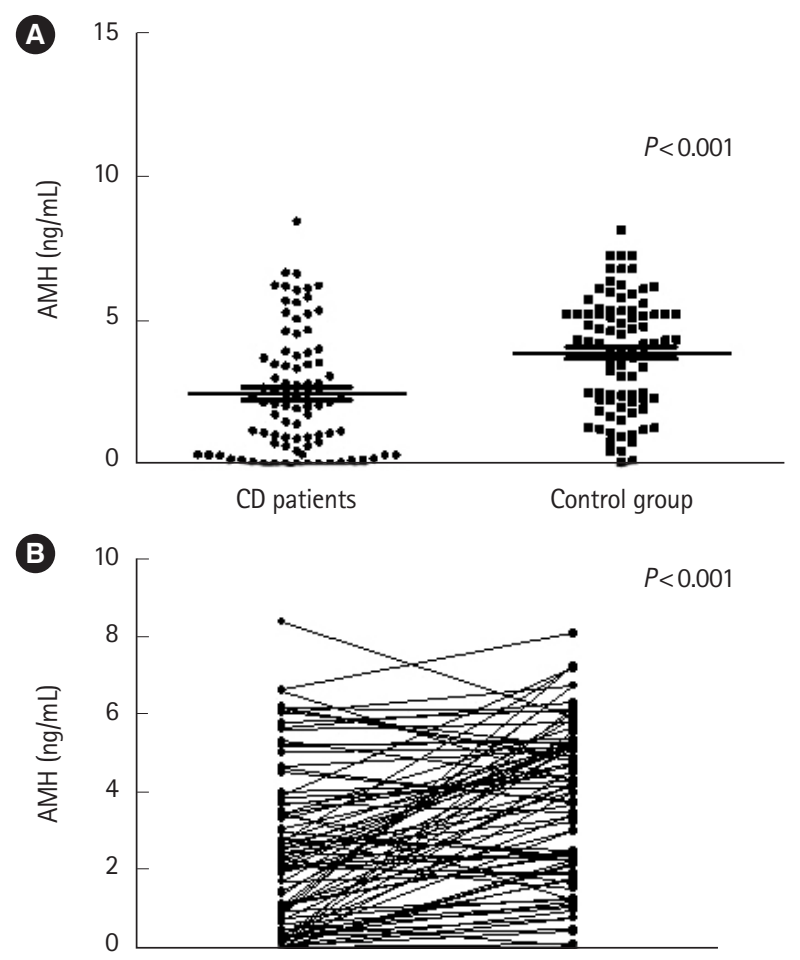

CD patients

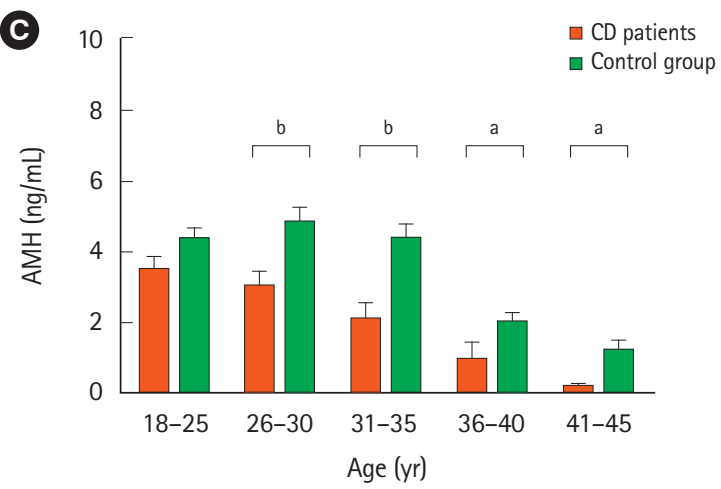

Fig. 1. The comparison of serum anti-Müllerian hormone (AMH) levels in $C D$ patients and healthy controls. (A) The serum AMH levels of female $C D$ patients and healthy controls. (B) The paired comparison of serum AMH level between $C D$ patients and matched controls. (C) The serum AMH levels of female $C D$ patients and healthy controls of different ages. ${ }^{a} P<0.05,{ }^{b} P<0.001$. 


\section{Correlation between Clinical Characteristics and AMH Levels}

The mean AMH level for the 43 CD patients in an active disease state was $1.34 \pm 1.39 \mathrm{ng} / \mathrm{mL}$, a lower value than both the 44 patients in remission $(3.52 \pm 2.09 \mathrm{ng} / \mathrm{mL}, P<0.001)$ and the control group $(3.87 \pm 1.96 \mathrm{ng} / \mathrm{mL}, P<0.001)$ (Fig. $2 \mathrm{~A})$. CD patients in a mildly active disease state showed higher serum
AMH levels than patients in a moderately/severe active disease state $(1.64 \pm 1.45 \mathrm{ng} / \mathrm{mL}$ vs. $0.38 \pm 0.34 \mathrm{ng} / \mathrm{mL}, P=0.007)$ (Fig. 2B).

Although the serum level of AMH was significantly lower in patients with stricturing $\mathrm{CD}(\mathrm{B} 2 ; 1.22 \pm 1.25 \mathrm{ng} / \mathrm{mL})$ compared with non-stricturing/penetrating $\mathrm{CD}(\mathrm{B} 1 ; 2.83 \pm 2.12 \mathrm{ng} / \mathrm{mL}$, $P=0.006$ ) (Fig. 2C), no significant difference was found between

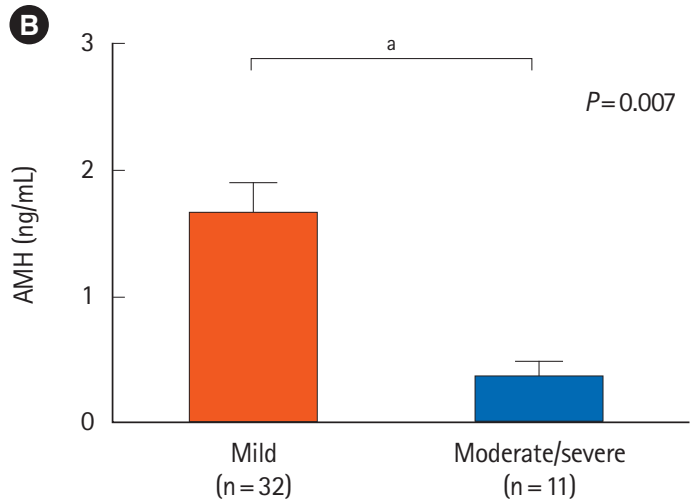

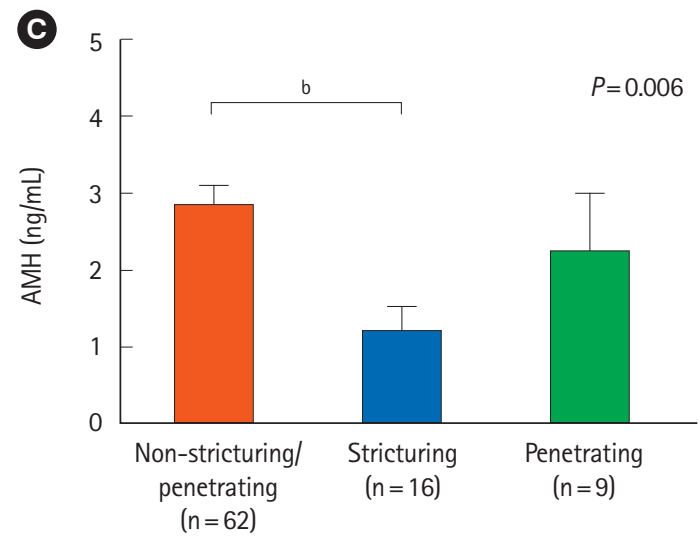
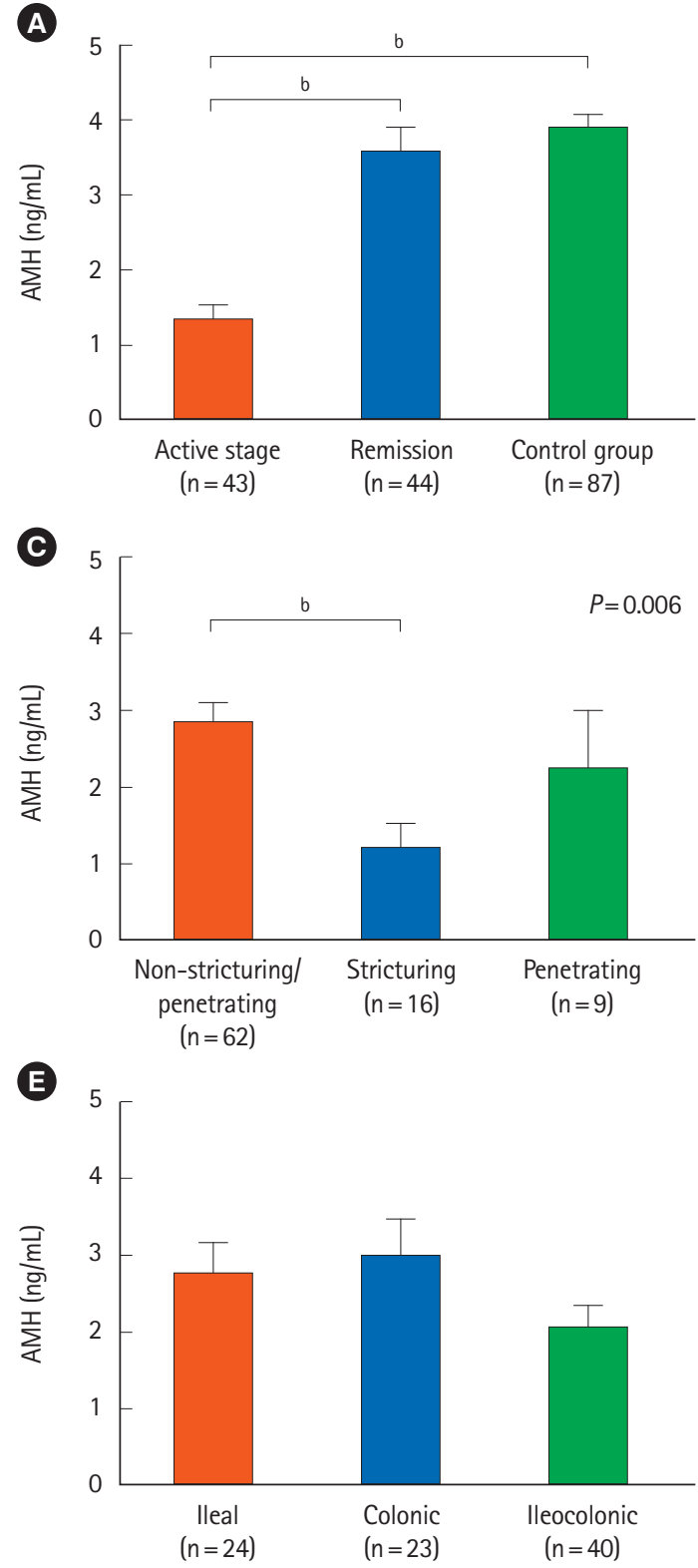
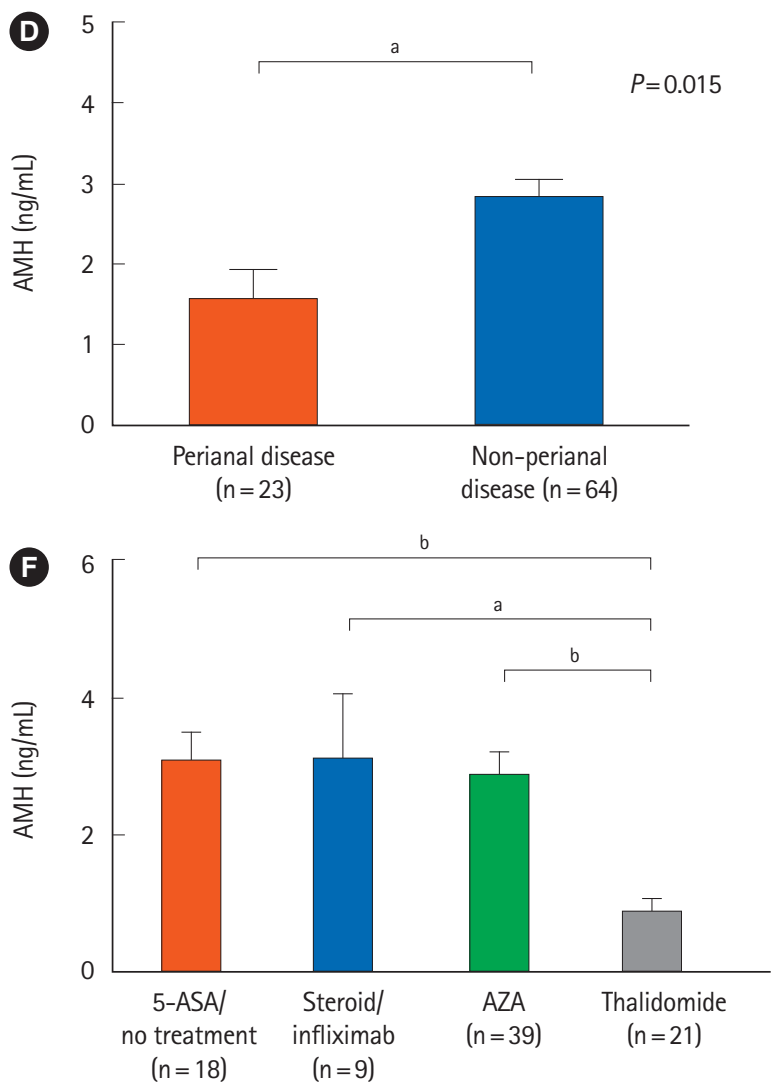

Fig. 2. The correlation between clinical characteristics and serum anti-Müllerian hormone (AMH) levels in CD patients of reproductive age. (A) Correlation between serum AMH levels and disease activity. (B) Correlation between serum AMH levels and disease severity. (C) Correlation between serum AMH levels and disease behavior. (D) Correlation between serum AMH levels and perianal lesions. (E) Correlation between serum AMH levels and disease location. (F) Correlation between serum AMH levels and medication usage. ${ }^{a} P<0.05$, ${ }^{\mathrm{b}} \mathrm{P}<0.001$. 
patients with non-stricturing/penetrating (B1) and penetrating CD (B3) patients $(2.24 \pm 2.29 \mathrm{ng} / \mathrm{mL}, P=0.418)$. CD patients with perianal disease $(1.57 \pm 1.71 \mathrm{ng} / \mathrm{mL})$ had lower serum AMH levels than patients without perianal disease $(2.80 \pm 2.12$ $\mathrm{ng} / \mathrm{mL}, P=0.015$ ) (Fig. 2D). When assessing disease location, we found that patients with ileocolonic CD (L3) were more likely to show lower serum AMH levels $(2.02 \pm 1.94 \mathrm{ng} / \mathrm{mL})$ than patients with ileal $\mathrm{CD}(\mathrm{Ll} ; 2.73 \pm 2.08 \mathrm{ng} / \mathrm{mL}, P=0.192)$ or colonic involved CD (L2; $2.97 \pm 2.23 \mathrm{ng} / \mathrm{mL}, P=0.081)$. However, none of these comparisons were statistically different (Fig. 2E).

Table 2. Univariate and Multivariable Analysis of Factors Associated with Low Ovarian Reserve (AMH $\leq 2 \mathrm{ng} / \mathrm{mL}$ ) in CD Female Patients

\begin{tabular}{|c|c|c|c|c|c|c|}
\hline \multirow[b]{2}{*}{ Characteristic } & \multicolumn{2}{|c|}{ AMH } & \multicolumn{2}{|c|}{ Univariable analysis } & \multicolumn{2}{|c|}{ Multivariable analysis } \\
\hline & $\begin{array}{c}\leq 2 \mathrm{ng} / \mathrm{mL} \\
(\mathrm{n}=38)\end{array}$ & $\begin{array}{c}>2 \mathrm{ng} / \mathrm{mL} \\
(\mathrm{n}=49)\end{array}$ & OR $(95 \% \mathrm{Cl})$ & $P$-value & OR $(95 \% \mathrm{Cl})$ & $P$-value \\
\hline \multicolumn{7}{|l|}{ Age (yr) } \\
\hline$\leq 25$ & 6 & 24 & Reference & & & \\
\hline$>25$ & 32 & 25 & $5.12(1.82-14.42)$ & 0.002 & $10.03(1.90-52.93)$ & 0.007 \\
\hline \multicolumn{7}{|l|}{ Duration (yr) } \\
\hline$\leq 6$ & 15 & 26 & Reference & & & \\
\hline$>6$ & 23 & 23 & $2.64(1.10-6.32)$ & 0.029 & & \\
\hline \multicolumn{7}{|c|}{ IBD related surgery historya } \\
\hline Yes & 8 & 5 & $2.35(0.70-7.87)$ & 0.167 & & \\
\hline No & 30 & 44 & Reference & & & \\
\hline \multicolumn{7}{|l|}{ Disease behavior } \\
\hline B1 & 23 & 39 & Reference & & & \\
\hline B2 & 11 & 5 & $3.70(1.15-12.09)$ & 0.028 & & \\
\hline B3 & 4 & 5 & $1.36(0.33-5.57)$ & 0.672 & & \\
\hline \multicolumn{7}{|l|}{ Perianal disease } \\
\hline Yes & 15 & 8 & $3.34(1.23-9.07)$ & 0.018 & & \\
\hline No & 23 & 41 & Reference & & & \\
\hline \multicolumn{7}{|l|}{ Disease activity } \\
\hline In remission & 7 & 37 & Reference & & & \\
\hline Active disease & 31 & 12 & $13.65(4.79-38.91)$ & $<0.001$ & $27.99(6.13-127.95)$ & $<0.001$ \\
\hline \multicolumn{7}{|l|}{ Location } \\
\hline L1 & 9 & 15 & Reference & & & \\
\hline L2 & 7 & 16 & $0.73(0.22-2.45)$ & 0.610 & & \\
\hline L3 & 22 & 18 & $2.04(0.74-5.73)$ & 0.178 & & \\
\hline \multicolumn{7}{|l|}{ Upper GI location ${ }^{b}$} \\
\hline Yes & 7 & 4 & $2.54(0.69-9.42)$ & 0.163 & & \\
\hline No & 31 & 45 & Reference & & & \\
\hline \multicolumn{7}{|l|}{ Medication history } \\
\hline 5-ASA/no treatment & 6 & 12 & Reference & & & \\
\hline Steroid/infliximab & 3 & 6 & $1.00(0.18-5.46)$ & 0.999 & & \\
\hline AZA & 12 & 27 & $0.89(0.27-2.93)$ & 0.847 & & \\
\hline Thalidomide & 17 & 4 & $8.50(1.96-36.79)$ & 0.004 & $15.66(2.22-110.65)$ & 0.006 \\
\hline
\end{tabular}

${ }^{a}$ Defined as any surgery that comprised of a diversion, stricturoplasty, and luminal resection, anytime during the follow-up period. Perianal abscess drainage or seton placement were not included.

'Includes all patients with upper GI tract disease associated with intestinal disease, instead of isolated upper GI disease.

AMH, anti-Müllerian hormone; B, behavior; L, location; 5-ASA, 5-aminosalicylic acid; AZA, azathioprine. 
The AMH levels of $\mathrm{CD}$ patients receiving thalidomide therapy $(0.89 \pm 0.93 \mathrm{ng} / \mathrm{mL})$ were significantly lower than the AMH levels of patients treated with 5-ASA or no medication (3.08 \pm 1.85 $\mathrm{ng} / \mathrm{mL}, P<0.001)$, AZA $(2.89 \pm 2.08 \mathrm{ng} / \mathrm{mL}, P<0.001)$ or ste$\mathrm{roid} /$ infliximab $(3.12 \pm 2.79 \mathrm{ng} / \mathrm{mL}, P=0.005)$. However, there was no significant difference in AMH levels among patients receiving 5-ASA or no medication, AZA and steroid/infliximab treatment (Fig. 2F). In addition, compared with normal control group, the AMH levels of 5-ASA/no treatment CD patient presented no statistical difference $(3.08 \pm 1.85 \mathrm{ng} / \mathrm{mL}$ vs. $3.87 \pm$

Table 3. Univariate and Multivariable Analysis of Factors Associated with Low Ovarian Reserve (AMH $\leq 1.1 \mathrm{ng} / \mathrm{mL}$ ) in CD Female Patients

\begin{tabular}{|c|c|c|c|c|c|c|}
\hline \multirow[b]{2}{*}{ Characteristic } & \multicolumn{2}{|c|}{ AMH } & \multicolumn{2}{|c|}{ Univariable analysis } & \multicolumn{2}{|c|}{ Multivariable analysis } \\
\hline & $\begin{array}{c}\leq 1.1 \mathrm{ng} / \mathrm{mL} \\
(\mathrm{n}=30)\end{array}$ & $\begin{array}{c}>1.1 \mathrm{ng} / \mathrm{mL} \\
(n=57)\end{array}$ & $\mathrm{OR}(95 \% \mathrm{Cl})$ & $P$-value & OR $(95 \% \mathrm{Cl})$ & $P$-value \\
\hline \multicolumn{7}{|l|}{ Age (yr) } \\
\hline$\leq 25$ & 4 & 26 & Reference & & & \\
\hline$>25$ & 26 & 31 & $5.45(1.68-17.65)$ & 0.005 & $15.28(2.08-112.08)$ & 0.007 \\
\hline \multicolumn{7}{|l|}{ Duration (yr) } \\
\hline$\leq 6$ & 13 & 33 & Reference & & & \\
\hline$>6$ & 17 & 24 & $1.79(0.73-4.39)$ & 0.198 & & \\
\hline \multicolumn{7}{|c|}{ IBD related surgery history ${ }^{2}$} \\
\hline Yes & 8 & 5 & $3.38(1.11-12.86)$ & 0.033 & & \\
\hline No & 22 & 52 & Reference & & & \\
\hline \multicolumn{7}{|l|}{ Disease behavior } \\
\hline B1 & 17 & 45 & Reference & & & \\
\hline B2 & 9 & 7 & $3.40(1.10-10.58)$ & 0.034 & & \\
\hline B3 & 4 & 5 & $2.12(0.58-8.83)$ & 0.303 & & \\
\hline \multicolumn{7}{|l|}{ Perianal disease } \\
\hline Yes & 12 & 11 & $2.79(1.04-7.45)$ & 0.041 & & \\
\hline No & 18 & 46 & Reference & & & \\
\hline \multicolumn{7}{|l|}{ Disease activity } \\
\hline In remission & 5 & 39 & Reference & & & \\
\hline Active disease & 25 & 18 & $10.83(3.57-32.90)$ & $<0.001$ & $36.27(4.69-147.23)$ & $<0.001$ \\
\hline \multicolumn{7}{|l|}{ Location } \\
\hline L1 & 7 & 17 & Reference & & & \\
\hline L2 & 6 & 17 & $0.86(0.23-3.09)$ & 0.814 & & \\
\hline L3 & 17 & 23 & $1.79(0.61-5.29)$ & 0.289 & & \\
\hline \multicolumn{7}{|l|}{ Upper GI location ${ }^{b}$} \\
\hline Yes & 6 & 5 & $2.60(0.72-9.37)$ & 0.144 & & \\
\hline No & 24 & 52 & Reference & & & \\
\hline \multicolumn{7}{|l|}{ Medication history } \\
\hline 5-ASA/no treatment & 3 & 15 & Reference & & & \\
\hline Steroid/infliximab & 2 & 7 & $1.43(0.19-10.58)$ & 0.727 & & \\
\hline AZA & 10 & 29 & $1.72(0.41-7.23)$ & 0.456 & & \\
\hline Thalidomide & 15 & 6 & $12.50(2.63-59.47)$ & 0.002 & $38.18(4.18-348.14)$ & 0.001 \\
\hline
\end{tabular}

${ }^{a}$ Defined as any surgery that comprised of a diversion, stricturoplasty, and luminal resection, anytime during the follow-up period. Perianal abscess drainage or seton placement were not included.

${ }^{6}$ Includes all patients with upper GI tract disease associated with intestinal disease, instead of isolated upper GI disease.

$\mathrm{AMH}$, anti-Müllerian hormone; B, behavior; L, location; 5-ASA, 5-aminosalicylic acid; AZA, azathioprine. 
$1.96 \mathrm{ng} / \mathrm{mL}, P=0.652)$.

\section{Risk Factors Associated with Low Ovarian Reserve}

When a low ovarian reserve was defined as a serum AMH level less than $2 \mathrm{ng} / \mathrm{mL}$, univariate analyses suggested that age greater than 25 (OR, 5.12; 95\% CI, 1.82-14.42; $P=0.002$ ), duration more than 6 years (OR, 2.64; 95\% CI, 1.10-6.34; $P=0.029)$, stricturing disease (B2) (OR, 3.70; 95\% CI, 1.15-12.09; $P=0.028)$, perianal disease (OR, 3.34; 95\% CI, 1.23-9.07; $P=0.018)$, active disease state (OR, 13.65; 95\% CI, 4.79-38.91; $P<0.001)$ and thalidomide use (OR, 8.50; 95\% CI, 1.96-36.79; $P=0.004)$ were associated with low ovarian reserve. Variables with $P<0.10$ (age greater than 25 years, duration more than 6 years, stricturing disease, perianal disease, active disease state, thalidomide use, and IBD related surgery history) were included in a multivariable logistic regression analysis. We found that age greater than 25 years $(\mathrm{OR}, 10.03 ; 95 \% \mathrm{CI}, 1.90-52.93 ; P=0.007)$, active disease state $(\mathrm{OR}, 27.99$; 95\% CI, 6.13-127.95; $P<0.001)$ and thalidomide use (OR, 15.66; 95\% CI, 2.22-110.65; $P=0.006$ ) were independent risk factors for low ovarian reserve (Table 2). On a secondary analysis of diminished ovarian reserve defined as AMH $\leq 1.1 \mathrm{ng} / \mathrm{mL}$, age greater than 25 years, active disease state and thalidomide use were still independent risk factors (Table 3).

\section{DISCUSSION}

AMH is a member of the transforming growth factor- $\beta$ (TGF- $\beta$ ) family and is produced by the granulose cells of preantral and small antral follicles. ${ }^{34}$ Together with antral follicle count, inhibin B and FSH concentration per cycle day, AMH levels have been used to measure ovarian reserve. ${ }^{25} \mathrm{AMH}$ remains stable throughout the menstrual cycle, thus has been replacing traditional FSH, luteinizing hormone, and estrogen tests of ovarian status in assisted reproductive technologies-in vitro fertilization $^{24}$ and malignancy chemotherapy, ${ }^{35}$ as well as in rheumatic diseases such as systemic lupus erythematosus ${ }^{36}$ and Behçet's disease. ${ }^{37} \mathrm{AMH}$ is currently considered the most accurate hormonal marker of ovarian reserve. The present study suggests that AMH levels are decreased in female CD patients over 25 years old, whereas serum AMH levels remained equivalent to controls in young women less than 25 years old. In contrast, Fréour et al. ${ }^{27}$ reported that AMH levels remained comparable between $\mathrm{CD}$ and control women over 30 years old, but levels were significantly lower in CD women under 30 years old. This difference in findings may be ascribed to the fact that only young women with CD in remission were included in the Fréour et al., ${ }^{27}$ while both active and remission patients were included in the current study.

Inflammatory burden related to $\mathrm{CD}$ plays an important role in fertility alterations, even without structural lesions in the gynecological system. ${ }^{28}$ In a study with small sample size of 35 female patients, Şenateş et al. ${ }^{28}$ reported a negative correlation between CDAI and serum AMH levels. Similarly, our study found that serum AMH levels were significantly lower in patients in an active disease state than for those in remission. Moreover, $\mathrm{CD}$ patients in a mildly active disease state showed higher serum AMH levels than patients in a moderately or severely active disease state. This finding may indicate that serum AMH levels are inversely correlated with the severity of CD activity.

Colonic location of $\mathrm{CD}$ has been reported to be independently associated with a high risk of altered ovarian reserve. ${ }^{27}$ However, through a multivariate analysis, our data suggest that disease location is not associated with a lower ovarian reserve. Although stricturing behavior and perianal disease are risk factors associated with poor outcome of $\mathrm{CD},{ }^{38-40}$ neither of these factors were correlated with lower ovarian reserve in our study, a finding that is inconsistent with previous studies. ${ }^{27}$ These data may imply that disease location and behavior may not have a direct impact on ovarian reserve, while disease activity might have direct impact on ovarian reserve.

Another novelty of the present study was a design that allowed us to investigate the potential impact of medication use on ovarian reserve. Indeed, whether medications, including steroid and immunosuppressive agents, can influence fertility outcomes is of great concern to both patients and doctors. Our results suggest that steroids, 5-ASA, thiopurines and infliximab have no significantly different effect on serum AMH levels compared with CD patients who had no medication or 5-ASA in reproductive age. However, thalidomide therapy was associated with lower ovarian reserve, which was in line with a previous study. ${ }^{29}$ These findings imply that ovarian reserve should be monitored in female $\mathrm{CD}$ patients of reproductive age who are using thalidomide. Thalidomide is an immunomodulatory drug used in some patients with CD refractory to first- or second-line therapy. Previous studies report that the overall prevalence of amenorrhea was $0.02 \%$ in patients using thalidomide. The immunosuppressive effects of thalidomide may also suppress functions of TGF- $\alpha$, TGF- $\beta$, or interleukin- $1 \beta$, which are important for the growth and development of primordium follicles and oocytes. ${ }^{42-45}$ Nevertheless, the exact mechanism of 
thalidomide effects on ovarian reserve, as well as possible ovarian reserve impairment reversals, remains to be clarified in future prospective studies.

Our study has certain limitations. First, limited data are currently available on reference values of AMH. We used $2 \mathrm{ng}$ / $\mathrm{mL}$, the value of 25th percentile in a healthy population with regular cycling. This value has been used previously as the diagnostic standard of low ovarian reserve. ${ }^{27}$ We also performed an additional analysis by defining diminished ovarian reserve as serum AMH levels below $1.1 \mathrm{ng} / \mathrm{mL}$, and similar results were found. Second, the influence of AMH levels on actual fertility outcomes was not reported in this cross-sectional study. Longterm prospective studies are needed to define the relationship between AMH levels and fertility results. Moreover, the impact of medication use on AMH level was analyzed by logistic analysis, and the numbers of included patients had some differences. There were only 4 patients received infliximab treatment, while 21 patients received thalidomide treatment in our study. Future studies with more cases, especially using infliximab are needed. In addition, the proportion of patients receiving thalidomide in our study seems to be relatively high. Due to medical reimbursement policy in China, a large number of refractory CD patients who cannot afford biologics such as infliximab, and thalidomide is a good option for them in such circumstance. ${ }^{46-48}$ More patients with different types of therapies will be included in future studies based on a great change in reimbursement policy recently, such as infliximab using, in China. Finally, a comparison of AMH levels before and after medical treatment is needed in a longitudinal study with more patients using biologics.

This study focused on the ovarian reserve and explored influencing factors of CD patients in reproductive age, which would guide patient's fertility in further clinical practice. In addition, our study also suggested that AMH assessment could be recommended for female CD patients who had fertility needs.

In conclusion, our study suggests that ovarian reserve is impaired in female CD patients compared to healthy controls. Age over 25 years old, active disease state and thalidomide use were independently associated with low ovarian reserve.

\section{FINANCIAL SUPPORT}

This work was supported by the National Natural Science Foundation of China (NSFC grant Nos. 81470821, 81270473, 81670607, and 81970483).

\section{CONFLICT OF INTEREST}

Chen M has received speaker fees from Janssen, Falk, Takeda, and Ipson. He Y has received speaker fees from Janssen, Falk, and Ipson. Ben-Horin S has received consultancy fees and/or research support from AbbVie, Schering-Plough, Janssen, Celltrion, and Takeda. No other potential conflict of interest relevant to this article was reported.

\section{AUTHOR CONTRIBUTION}

Conceptualization: Chen M, Zhao Y, Chen B, He Y. Methodology: Zhao Y. Formal analysis: Zhao Y. Funding acquisition: Chen M, Zhang S, Mao R. Project administration: Qiu Y, Feng R, Yang H. Visualization: Zeng Z. Writing - original draft: Zhao Y, Mao R. Writing: Mao R, Ben-Horin S. Approval of final manuscript: all authors.

\section{ORCID}

Zhao Y https://orcid.org/0000-0001-8834-1069

Chen B https://orcid.org/0000-0002-7905-9499

Mao R https://orcid.org/0000-0002-5523-8185

\section{REFERENCES}

1. Duricova D, Burisch J, Jess T, Gower-Rousseau C, Lakatos PL; ECCO-EpiCom. Age-related differences in presentation and course of inflammatory bowel disease: an update on the population-based literature. J Crohns Colitis 2014;8:1351-1361.

2. Burisch J, Pedersen N, Čuković-Čavka S, et al. East-West gradient in the incidence of inflammatory bowel disease in Europe: the ECCO-EpiCom inception cohort. Gut 2014;63:588-597.

3. Dignass A, Eliakim R, Magro F, et al. Second European evidence-based consensus on the diagnosis and management of ulcerative colitis part 1: definitions and diagnosis. J Crohns Colitis 2012;6:965-990.

4. Lakatos L, Kiss LS, David G, et al. Incidence, disease phenotype at diagnosis, and early disease course in inflammatory bowel diseases in Western Hungary, 2002-2006. Inflamm Bowel Dis 2011;17:2558-2565.

5. Loftus CG, Loftus EV Jr, Harmsen WS, et al. Update on the incidence and prevalence of Crohn's disease and ulcerative colitis in Olmsted County, Minnesota, 1940-2000. Inflamm Bowel Dis 2007;13:254-261.

6. Shivananda S, Lennard-Jones J, Logan R, et al. Incidence of in- 
flammatory bowel disease across Europe: is there a difference between north and south? Results of the European Collaborative Study on Inflammatory Bowel Disease (EC-IBD). Gut 1996; 39:690-697.

7. Moum B, Vatn MH, Ekbom A, et al. Incidence of ulcerative colitis and indeterminate colitis in four counties of southeastern Norway, 1990-93: a prospective population-based study: the Inflammatory Bowel South-Eastern Norway (IBSEN) Study Group of Gastroenterologists. Scand J Gastroenterol 1996;31: 362-366.

8. Hudson M, Flett G, Sinclair TS, Brunt PW, Templeton A, Mowat NA. Fertility and pregnancy in inflammatory bowel disease. Int J Gynaecol Obstet 1997;58:229-237.

9. Khosla R, Willoughby CP, Jewell DP. Crohn's disease and pregnancy. Gut 1984;25:52-56.

10. Cornish JA, Tan E, Teare J, et al. The effect of restorative proctocolectomy on sexual function, urinary function, fertility, pregnancy and delivery: a systematic review. Dis Colon Rectum 2007;50:1128-1138.

11. Mountifield R, Bampton P, Prosser R, Muller K, Andrews JM. Fear and fertility in inflammatory bowel disease: a mismatch of perception and reality affects family planning decisions. Inflamm Bowel Dis 2009;15:720-725.

12. Marri SR, Ahn C, Buchman AL. Voluntary childlessness is increased in women with inflammatory bowel disease. Inflamm Bowel Dis 2007;13:591-599.

13. Johnson P, Richard C, Ravid A, et al. Female infertility after ileal pouch-anal anastomosis for ulcerative colitis. Dis Colon Rectum 2004;47:1119-1126.

14. Olsen KO, Joelsson M, Laurberg S, Oresland T. Fertility after ileal pouch-anal anastomosis in women with ulcerative colitis. Br J Surg 1999;86:493-495.

15. Seiler JS. Pelvic pathology affecting fertility. Int J Fertil 1987;32: 208-212.

16. Oresland T, Palmblad S, Ellström M, Berndtsson I, Crona N, Hultén L. Gynaecological and sexual function related to anatomical changes in the female pelvis after restorative proctocolectomy. Int J Colorectal Dis 1994;9:77-81.

17. McHugh SM, Rifkin IR, Deighton J, et al. The immunosuppressive drug thalidomide induces T helper cell type 2 (Th2) and concomitantly inhibits Thl cytokine production in mitogenand antigen-stimulated human peripheral blood mononuclear cell cultures. Clin Exp Immunol 1995;99:160-167.

18. Arkuran C, McComb P. Crohn's disease and tubal infertility: the effect of adhesion formation. Clin Exp Obstet Gynecol 2000;27:12-13.
19. Diamond MP, Freeman ML. Clinical implications of postsurgical adhesions. Hum Reprod Update 2001;7:567-576.

20. Selinger CP, Eaden J, Selby W, et al. Patients' knowledge of pregnancy-related issues in inflammatory bowel disease and validation of a novel assessment tool ('CCPKnow'). Aliment Pharmacol Ther 2012;36:57-63.

21. Maheshwari A, Fowler P, Bhattacharya S. Assessment of ovarian reserve: should we perform tests of ovarian reserve routinely? Hum Reprod 2006;21:2729-2735.

22. van Rooij IA, Broekmans FJ, Hunault CC, et al. Use of ovarian reserve tests for the prediction of ongoing pregnancy in couples with unexplained or mild male infertility. Reprod Biomed Online 2006;12:182-190.

23. Broekmans FJ, Kwee J, Hendriks DJ, Mol BW, Lambalk CB. A systematic review of tests predicting ovarian reserve and IVF outcome. Hum Reprod Update 2006;12:685-718.

24. La Marca A, Giulini S, Tirelli A, et al. Anti-Müllerian hormone measurement on any day of the menstrual cycle strongly predicts ovarian response in assisted reproductive technology. Hum Reprod 2007;22:766-771.

25. La Marca A, Stabile G, Artenisio AC, Volpe A. Serum anti-Mullerian hormone throughout the human menstrual cycle. Hum Reprod 2006;21:3103-3107.

26. Dayal M, Sagar S, Chaurasia A, Singh U. Anti-Mullerian hormone: a new marker of ovarian function. J Obstet Gynaecol India 2014;64:130-133.

27. Fréour T, Miossec C, Bach-Ngohou K, et al. Ovarian reserve in young women of reproductive age with Crohn's disease. Inflamm Bowel Dis 2012;18:1515-1522.

28. Şenateş E, Çolak Y, Erdem ED, et al. Serum anti-Müllerian hormone levels are lower in reproductive-age women with Crohn's disease compared to healthy control women. J Crohns Colitis 2013; 7:e29-e34.

29. Peng X, Zhi M, Wei M, et al. Thalidomide results in diminished ovarian reserve in reproductive age female IBD patients. Medicine (Baltimore) 2017;96:e6540.

30. La Marca A, Sighinolfi G, Giulini S, et al. Normal serum concentrations of anti-Müllerian hormone in women with regular menstrual cycles. Reprod Biomed Online 2010;21:463-469.

31. Ferraretti AP, La Marca A, Fauser BC, et al. ESHRE consensus on the definition of 'poor response' to ovarian stimulation for in vitro fertilization: the Bologna criteria. Hum Reprod 2011; 26:1616-1624.

32. Mearin F, Lacy BE, Chang L, et al. Bowel disorders. Gastroenterology 2016;150:1393-1407.

33. Chow SC, Shao J, Wang H. Sample size calculations in clinical 
research. Boca Raton: Chapman \& Hall/CRC Biostatistics Series, 2008

34. van Rooij IA, Broekmans FJ, te Velde ER, et al. Serum anti-Müllerian hormone levels: a novel measure of ovarian reserve. Hum Reprod 2002;17:3065-3071.

35. Iwase A, Nakamura T, Nakahara T, Goto M, Kikkawa F. AntiMüllerian hormone and assessment of ovarian reserve after ovarian toxic treatment: a systematic narrative review. Reprod Sci 2015;22:519-526.

36. Browne H, Armstrong A, Decherney A, et al. Assessment of ovarian function with anti-Müllerian hormone in systemic lupus erythematosus patients undergoing hematopoietic stem cell transplant. Fertil Steril 2009;91(4 Suppl):1529-1532.

37. Henes M, Froeschlin J, Taran FA, et al. Ovarian reserve alterations in premenopausal women with chronic inflammatory rheumatic diseases: impact of rheumatoid arthritis, Behçet's disease and spondyloarthritis on anti-Müllerian hormone levels. Rheumatology (Oxford) 2015;54:1709-1712.

38. Chen M, Shen B. Comparable short- and long-term outcomes of colonoscopic balloon dilation of Crohn's disease and benign non-Crohn's disease strictures. Inflamm Bowel Dis 2014; 20:1739-1746.

39. Veloso FT. Clinical predictors of Crohn's disease course. Eur J Gastroenterol Hepatol 2016;28:1122-1125.

40. Bharadwaj S, Fleshner P, Shen B. Therapeutic armamentarium for stricturing Crohn's disease: medical versus endoscopic versus surgical approaches. Inflamm Bowel Dis 2015;21:21942213.

41. Lazzerini M, Bramuzzo M, Martelossi S, Magazzù G, Pellegri- no S, Ventura A. Amenorrhea in women treated with thalidomide: report of two cases and literature review. Inflamm Bowel Dis 2013;19:E10-E11.

42. Song T, Ma X, Gu K, et al. Thalidomide represses inflammatory response and reduces radiculopathic pain by inhibiting IRAK-1 and NF-кB/p38/JNK signaling. J Neuroimmunol 2016; 290:1-8.

43. Amirshahrokhi K, Khalili AR. The effect of thalidomide on ethanol-induced gastric mucosal damage in mice: involvement of inflammatory cytokines and nitric oxide. Chem Biol Interact 2015;225:63-69.

44. Amirshahrokhi K. Anti-inflammatory effect of thalidomide in paraquat-induced pulmonary injury in mice. Int Immunopharmacol 2013;17:210-215.

45. Sharma GT, Dubey PK, Kumar GS. Effects of IGF-1, TGF-alpha plus TGF-betal and bFGF on in vitro survival, growth and apoptosis in FSH-stimulated buffalo (Bubalis bubalus) preantral follicles. Growth Horm IGF Res 2010;20:319-325.

46. Bramuzzo M, Ventura A, Martelossi S, Lazzerini M. Thalidomide for inflammatory bowel disease: systematic review. Medicine (Baltimore) 2016;95:e4239.

47. He Y, Mao R, Chen F, et al. Thalidomide induces clinical remission and mucosal healing in adults with active Crohn's disease: a prospective open-label study. Therap Adv Gastroenterol 2017;10:397-406.

48. Zhu Z, Li M, Shu X, et al. Thalidomide is a therapeutic agent that is effective in inducing and maintaining endoscopic remission in adult CD patients. Clin Res Hepatol Gastroenterol 2017;41:210-216. 